\title{
Tissue-Specific Localization NUCB2/nesfatin-1 in the Liver and Heart of Mouse Fetus
}

\author{
Sojung Sun and Hyunwon Yang \\ Dept. of Bioenvironmental Technology, College of Natural Sciences, Seoul Women's University, Seoul 01797, Korea
}

\begin{abstract}
NUCB2/nesfatin-1 is first known to be expressed in the hypothalamus while controlling appetite and energy metabolism. However, recent studies have shown that NUCB2/nesfatin-1 was expressed in the various organs as well as the hypothalamus. Our previous reports also demonstrated that NUCB2/nesfatin-1 was expressed in the ovary, testis, pituitary gland, lung, kidney, and stomach of fetal and adult mice. However, the role of NUCB2/nesfatin-1 in mouse fetus remains unknown. Thus, the aim of this study was to investigate whether NUCB2/nestatin-1 is expressed in mouse fetus at the developmental stage in which organogenesis begins. To do this, we performed in situ hybridization (ISH) and immunohistochemistry (IHC) staining to examine the distribution of NUCB2 mRNA and nesfatin-1 protein in the mouse fetal organs during early developmental stages, especially at embryonic day (E) 10.5. As a result of ISH, NUCB2 mRNA positive signals were more frequent in the liver, but there were relatively few positive signals in heart. On the other hand, no positive signals were detected in other organs. These ISH results were validated by IHC staining and qRT-PCR analysis. Expression of nesfatin1 protein detected by IHC staining was similar to that of NUCB 2 mRNA detected by ISH in the liver and heart. In addition, the levels of NUCB2 mRNA expression analyzed by qRT-PCR were significantly increased in the liver and heart compared to other organs of the mouse fetus at E13.5, whereas its level was extensively decreased in the liver, but increased in the lung, stomach, and kidney of the mouse fetus at E17.5. These results suggest that NUCB2/nesfatin-1 may play an important role in liver and heart development and physiological functions in the developmental process of mouse fetus. Further studies are needed on the function of NUCB2/nesfatin-1, which is highly expressed in the various organs, including liver and heart during mouse development.
\end{abstract}

Key words : : In situ hybridization, Mouse fetus, NUCB2/nesfatin-1, Organogenesis

\section{INTRODUCTION}

Nesfatin-1 is a polypeptide encoded in the N-terminal region of the protein precursor, nucleobindin-2 (NUCB2), which also produces nesfatin- 2 and -3 by the enzyme pro- hormone convertase (PC)-1/3 after putative post-translational processing (Miura et al., 1992; Barnikol-Watanabe et al., 1994). Nesfatin-1 has been known to have only physiological activity so far (Oh-I et al., 2006; Stengel et al., 2012; Schalla \& Stengel, 2018).

\footnotetext{
Manuscript received October 29, 2018, Received in revised form November 17, 2018, Accepted December 5, 2018

${ }^{\dagger}$ Corresponding Author : Hyunwon Yang, Dept. of Bioenvironmental Technology, College of Natural Sciences, Seoul Women's University, Seoul 01797, Korea. Tel: +82-2-970-5662, Fax: +82-2-970-5974, E-mail: hwyang@swu.ac.kr
}

This is an Open Access article distributed under the terms of the Creative Commons Attribution Non-Commercial License (http:// creative-commons.org/licenses/by-nc/3.0) which permits unrestricted non-commercial use, distribution, and reproduction in any medium, provided the original work is properly cited. 


\section{S Sun, H Yang}

Nesfatin-1 is initially known to be expressed in the hypothalamic nuclei such as arcuate nucleus, paraventricular nucleus, supraoptic nucleus, lateral hypothalamic area and zona incerta in rats (Brailoiu et al., 2007; Foo et al., 2008; Goebel et al., 2009; Xu et al., 2009; Stengel et al., 2010; GoebelStengel et al., 2011). Recent studies showed that a large amount of the nesfatin-1 expression was detected in the digestive system as well as in the brain. It has been also reported that the nesfatin-1 generated in the gastric organs, by acting in the brain, reduces food intake and suppresses the motilities of the stomach-duodenum (Jiang et al., 2016; Prinz et al., 2016). Nesfatin-1 immunoreactive cells are also co-localized with insulin in pancreatic beta-cells of mice and rats, suggesting a potential role for nesfatin-1 in pancreatic islet and glucose homeostasis (Gonzalez et al., 2009). Furthermore, nesfatin-1 was detected in the adipose tissues of humans and rodents, showing that it was expressed more in the subcutaneous than in the visceral fat (Shimizu et al., 2016).

Expression of NUCB2 mRNA has been detected in rat, mouse, dog, and human reproductive system (Garcia-Galiano et al., 2010; Garcia-Galiano et al., 2012; Nozawa et al., 2016). We also previously demonstrated that NUCB2/ nesfatin-1 is expressed in the mouse hypothalamus and pituitary and its expression levels were regulated by the gonadotropin (Kim et al., 2014; Chung et al., 2015, Seon et al., 2017). Moreover, the expression of NUCB2/nesfatin-1 in the pituitary and hypothalamus is regulated by estradiol and progesterone secreted from the ovary (Chung et al., 2015). Nesfatin-1 was also implicated in the maintenance of pregnancy because uterine expression levels of NUCB2/nesfatin1 were increased in a mouse spontaneous abortion model (Chung et al., 2017).

Organogenesis is a crucial process during embryonic development of all animals, leading to the various organs in the body. Organogenesis starts with neural tube formation and cells in mesoderm layer are segmented into somites (Cunha \& Baskin, 2016). The onset of mouse organogenesis has been known to begin at approximately E8.0, and the buds of all major organs are essentially formed at E9.5 (Cunha \& Baskin, 2016). Around that time, many organogenesis-related genes and proteins are involved in the mouse fetal development and their interaction is crucial for the proper development of all organs (Baskin et al., 1996; Cunha \& Baskin, 2016). Our previous reports have demonstrated that NUCB2/nestatin-1 was expressed in the fetus at embryonic day (E) 18.5 as well as neonatal and adult mice, suggesting that NUCB2/nestatin-1 may involved in the development and physiological function in mouse organs (Chung et al., 2013). Moreover, to further reinforce the hypothesis that NUCB2/nestatin-1 may involved in the organogenesis of mouse, it is needed to analyze expression in fetuses before E18.5 in mouse development. However, it is difficult to harvest organs of fetuses at E8.0 to E10.5, which is a critical time for mouse organogenesis, since the size of the fetus at that time is too small to obtain organs for qRTPCR and Western blot analysis.

The aim of this study was therefore to investigate whether NUCB2/nestatin-1 is expressed in the fetuses earlier than E18.5, especially the fetus at E10.5. In this study, to identify the NUCB2 mRNA expression sites in specific organs, we focused on localization of NUCB2 mRNA in various organs of mouse fetus at E10.5 using in situ hybridization (ISH) method. In addition, we validated ISH results by immunofluorescence staining and qRT-PCR analysis.

\section{MATERIALS AND METHODS}

\section{Animals}

Pregnant ICR mice were purchased from Samtako Bio Korea (South Korea) and housed in groups of five per cage under controlled illumination (12:12 h light/dark cycle, lights on/off: $6 \mathrm{~h} / 18 \mathrm{~h})$ and temperature $\left(22 \pm 2^{\circ} \mathrm{C}\right)$. Animals were fed a standard rodent diet and tap water ad libitum. Animal care and experimental procedures were approved by the Institutional Animal care and the use committee at the Seoul Women's University in accordance with guidelines 
established by the Korea Food and Drug Administration.

\section{Tissue section preparation}

To prepare sections of mouse fetus for ISH and IHC staining, pregnant mice at embryonic day (E)10.5 were euthanized by $\mathrm{CO}_{2}$ anesthesia. Fetuses were harvested after abdominal incision and fixed with $4 \%$ paraformaldehyde in HEPES buffer (30 mM HEPES, $100 \mathrm{mM} \mathrm{NaCl,} 2 \mathrm{mM}$ $\mathrm{CaCl}_{2}, \mathrm{pH}$ 7.4). For paraffin embedding, fetuses were dehydrated in a graded series of alcohols, cleared with xylene, and embedded in paraffin (Paraplast Plus, Sigma, St. Louis, MO, USA). To prepare fresh organs of fetus at E13.5 and E17.5 for qRT-PCR, pregnant mice were euthanized by $\mathrm{CO}_{2}$ anesthesia and organs were quickly removed. The samples were kept in the ice and stored at $-70^{\circ} \mathrm{C}$ until using them.

\section{In situ hybridization (ISH)}

The NUCB2 mRNA expression in the mouse fetus was examined by RNA ISH using the RNA scope technology (Advanced Cell Diagnostics, Hayward, CA, USA) according to the manufacturer's instruction. The paraffin embedded tissue section slides were baked for $1 \mathrm{~h}$ at $60^{\circ} \mathrm{C}$ prior to use. After de-paraffinization and dehydration, the tissues were air dried and treated with hydrogen peroxide before boiling at $95^{\circ} \mathrm{C}$ in a $1 \times$ Target Retrieval solution for $15 \mathrm{~min}$. Protease was then applied for $30 \mathrm{~min}$ at $40^{\circ} \mathrm{C}$. NUCB2 probe was hybridized for $2 \mathrm{~h}$ at $40^{\circ} \mathrm{C}$, followed by a series of signal amplification which were hybridized to the target probes, and washing steps, and then color was developed with DAB. All hybridizations at $40^{\circ} \mathrm{C}$ were performed in a HybEZ Hybridization System. Sections were then counterstained with 50\% Mayer's hematoxylin diluted in distilled water for $2 \mathrm{~min}$ and dehydrated through ascending ethanol and xylene and Permanent Mounting Medium (Dako, CA, USA). Bright field images were acquired using a Leica microscope using a $40 \times$ objective. Negative control background staining was evaluated using a probe specific to the bacterial dapB gene.

\section{Immunohistochemistry staining}

The tissues embedded in paraffin were cut $10 \mu \mathrm{m}$ sections using a microtome, deparaffinized, and rehydrated with graded xylene-alcohol series, and then washed with PBS before immunostaining. The sections were incubated with rabbit anti-rat nesfatin-1 polyclonal antibody (Phoenix Pharmaceuticals, INC., Burlingame, CA, USA) at $4^{\circ} \mathrm{C}$ for overnight followed by incubation with Alexa fluor 594 conjugated goat anti-rabbit IgG (Jackson immuno research laboratory, West grove, PA, USA). The sections were counter stained with DAPI (4',6-diamidino-2-phenylindole; Sigma, St. Louis, MO, USA) for $10 \mathrm{~min}$ and mounted on the slides with mounting medium (Vector laboratories, INC., Burlingame, CA, USA), and then observed under fluorescence microscopy (Axioskop2, Carl Zeiss, Germany).

\section{RNA extraction and qRT-PCR}

Frozen organs were homogenized with $300 \mu \mathrm{L}$ ice cold RNA isoplus (TaKaRa Bio, Shiga, Japan). After chloroform extraction and isopropyl alcohol precipitation, RNA was dissolved in $20 \mu \mathrm{L}$ RNase-free DEPC (TaKaRa Bio, Shiga, Japan) solution. The RNA concentrations were measured with the Nano-drop (Thermo Fisher Scientific Inc., Waltham, MA, USA). First strand cDNA synthesis was performed using $2 \mu \mathrm{g}$ RNA, 10 pmol oligo dT and RNase-free DEPC solution at $70^{\circ} \mathrm{C}$ for $5 \mathrm{~min}$, followed by double-strand synthesis in 5× RT buffer (Invitrogen, Carlsbad, CA, USA) with $8 \mathrm{mM}$ dNTP (BIO BASIC INC., Ontario, Canada), 200 unit/ $\mu \mathrm{L}$ RTase (Invitrogen, Carlsbad, CA, USA) and RNase-free DEPC solution at $37^{\circ} \mathrm{C}$ for $60 \mathrm{~min}$ and at $72^{\circ} \mathrm{C}$ for 15 min. qRT-PCR was performed in a total volume of $20 \mu \mathrm{L}$ buffer solution containing $2 \mu \mathrm{L}$ of template cDNA, $10 \mu \mathrm{L}$ of SYBR Green (Roche, Manheim, Germany), and 10 pmol of each primer. Primer pairs were as follows: NUCB2 forward 5'-AAAACCTTGGCCTGTCTGAA-3'; reverse 5'-CATCGATAGGAACAGCTTCCA-3' and GAPDH forward 5'-TTGATGGCAACAATCTCCAC-3'; reverse 5'CGTCCCGTAGACAAAATGGT-3' (BIONICS, Seoul, Ko- 
rea). The optimal temperature cycling protocol was determined to be $95^{\circ} \mathrm{C}$ for 5 min followed by 45 reaction cycles at $95^{\circ} \mathrm{C}$ for $10 \mathrm{~s}, 60^{\circ} \mathrm{C}$ for $10 \mathrm{~s}$ and $72^{\circ} \mathrm{C}$ for $10 \mathrm{~s}$ using the LightCycler $^{\circledR} 480$ Real-time PCR System (Roche, Manheim, Germany).

\section{RESULTS}

\section{Localization of NUCB2 mRNA in mouse fetal liver} and heart by in situ hybridization

The localization of NUCB2 mRNA in the mouse fetus was verified by a highly-sensitive ISH system using NUCB2 probe. The positive signals were present as punc- tate cytoplasmic and/or nuclear brown staining that was higher than the signals on the negative control slide (Fig. 2C, D). Fig. 1 shows that NUCB2 mRNA was localized in the liver and heart of mouse fetus at E10.5. Many of dark brown dots as positive signal were observed in the liver (Fig. 1D, E), while relatively less positive signals were in the heart (Fig. 1C, F). On the other hand, no positive signals were detected in other organs of the mouse fetus at E10.5. As a positive control for NUCB2 mRNA ISH, we used the pituitary gland of adult mouse, in which NUCB2/nesfatin-1 is expressed a lot (Kim et al., 2014; Chung et al., 2015). Strong positive signals in pituitary gland slides established the validity of ISH results in the liver and heart (Fig. 2A, B).
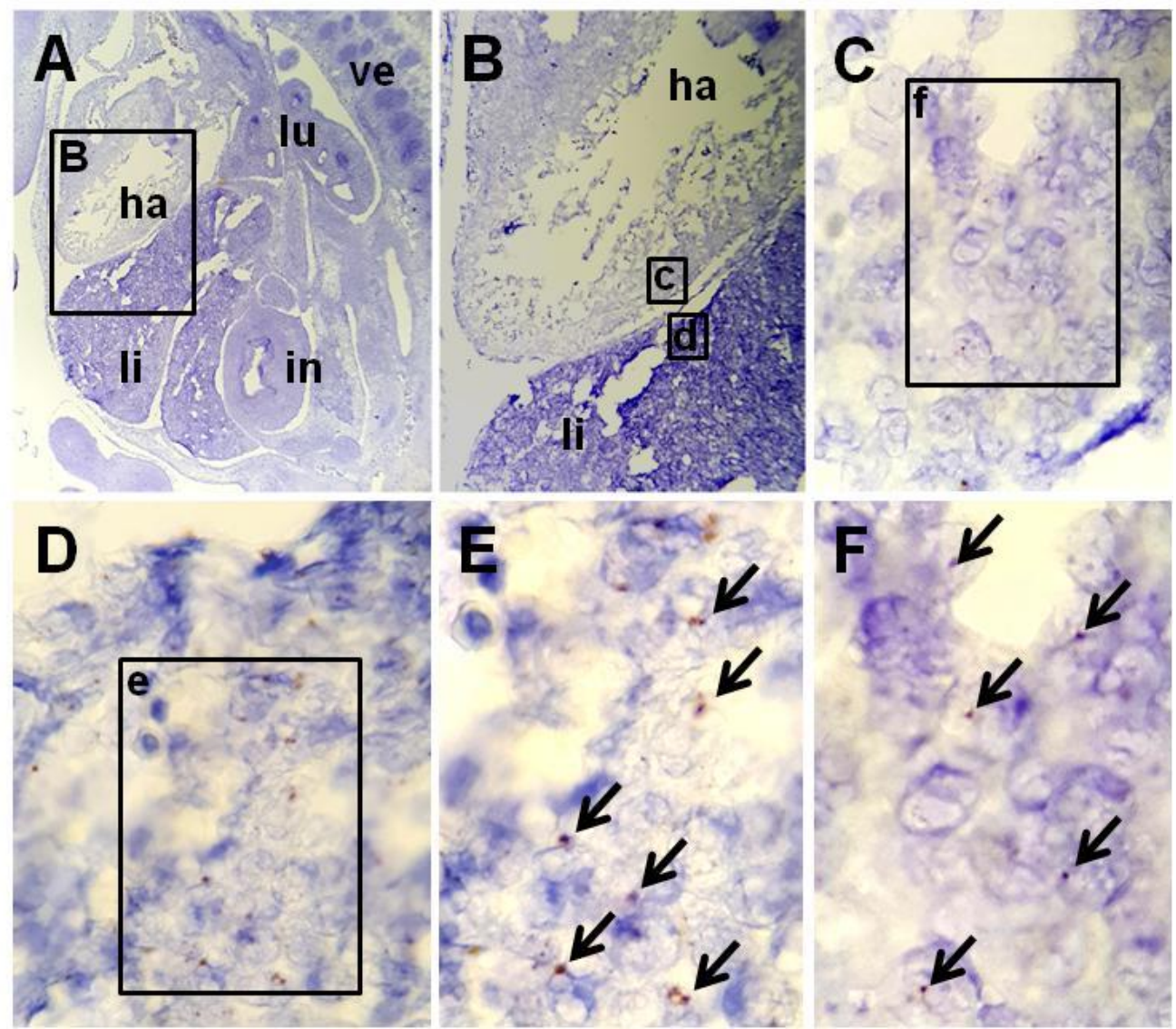

Fig. 1. Localization of NUCB2 mRNA in mouse fetus at E10.5 by high-sensitive in situ hybridization. The positive signals for NUCB2 mRNA were present as punctate cytoplasmic and/or nuclear brown staining. Many of dark brown dots as positive signal were observed in the liver (A, B, D, E), while relatively less positive signals were in the heart (A, B, C, F). ha, heart; in, intestine; li, liver; lu, lung; ve, vertebrae. Original magnification (A) $100 \times$, (B) $200 \times(C$, D) $400 \times,(E, F) 1,000 \times$. 


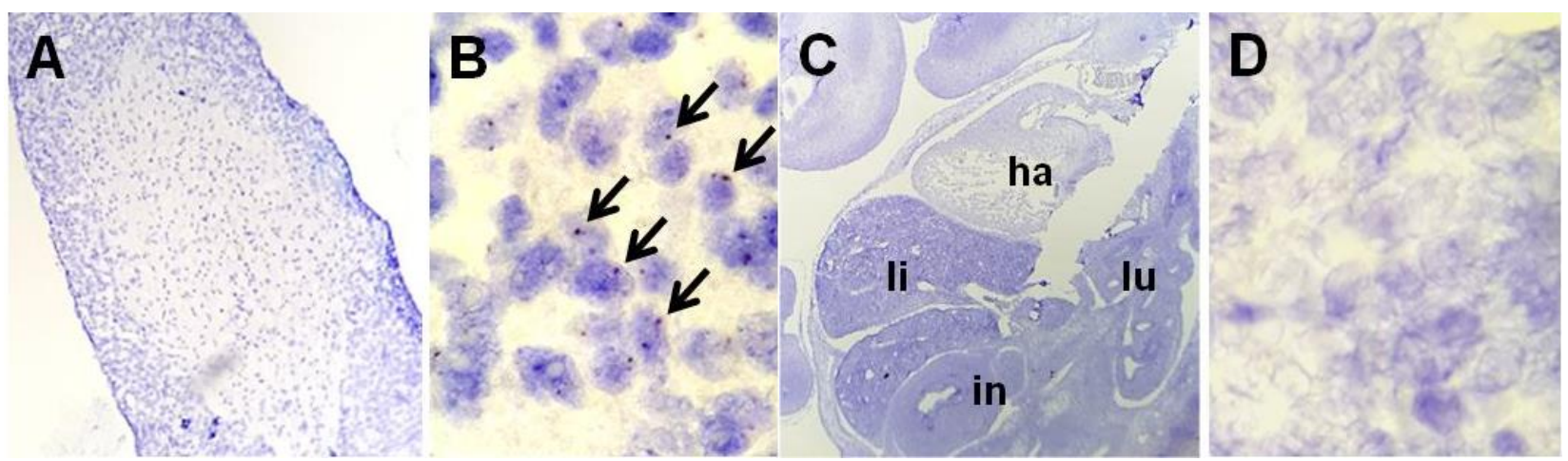

Fig. 2. Localization of NUCB2 mRNA in pituitary gland of adult mouse by high-sensitive in situ hybridization (ISH). The pituitary gland of adult mouse, in which NUCB2 mRNA is expressed a lot, was used as a positive control for ISH. Pituitary gland represents many brown dots as positive signals (A, B). On the other hand, no positive signals were detected in other organs of the mouse fetus at E10.5 (C, D). ha, heart; in, intestine; li, liver; lu, lung. Original magnification $(\mathrm{A}, \mathrm{C}) 100 \times$, (B, D) $1,000 \times$.

The pituitary gland of adult mouse was used as a positive control for ISH.

2. Immunofluorescence staining of nesfatin-1 in mouse fetal liver and heart

The localization of NUCB2 mRNA in the mouse fetus was further verified by immunofluorescence staining for nesfatin-1 protein. In accordance with ISH results, nesfatin-

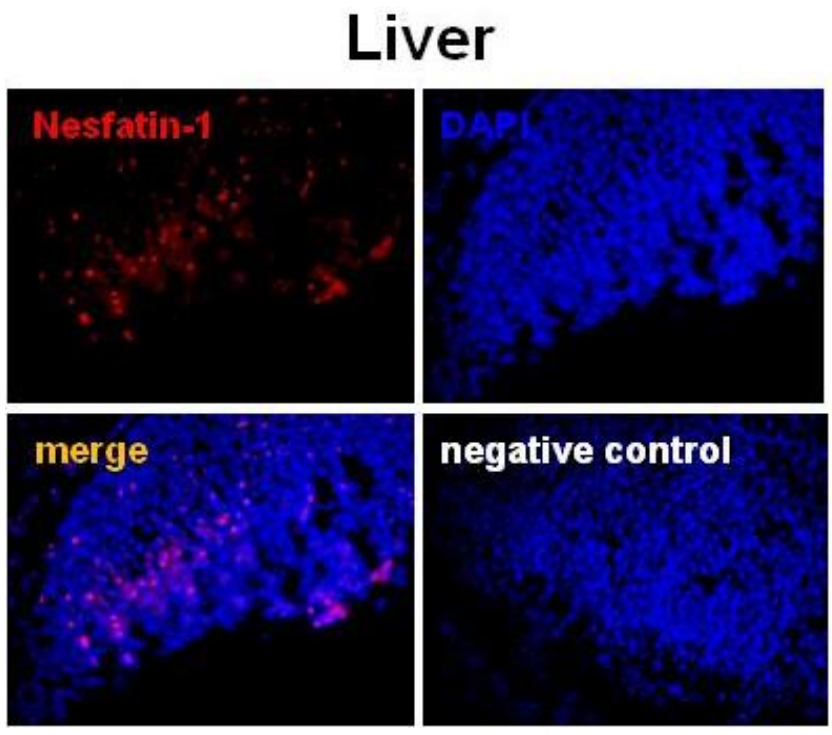

1 protein was expressed in the liver and heart of the mouse fetus at E10.5, where NUCB2 mRNA was detected by ISH (Fig. 3). Many cells stained with red fluorescence were observed in the liver and heart, whereas no cells stained with red were detected on the negative control slide (Fig. 3).

3. NUCB2 mRNA expression levels in mouse fetus The expression of NUCB2 mRNA in the various organs

\section{Heart}
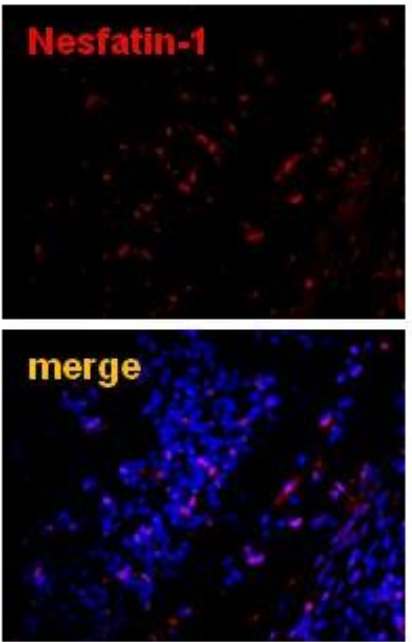

Fig. 3. Immunofluorescence staining of nestatin-1 protein in mouse fetus at E10.5. Nesfatin-1 protein was expressed in the liver and heart, where NUCB2 mRNA was detected by ISH (in situ hybridization). Many cells stained with red fluorescence were observed in the liver and heart, whereas no cells stained with red were detected on the negative control slide. Original magnification 200×. 


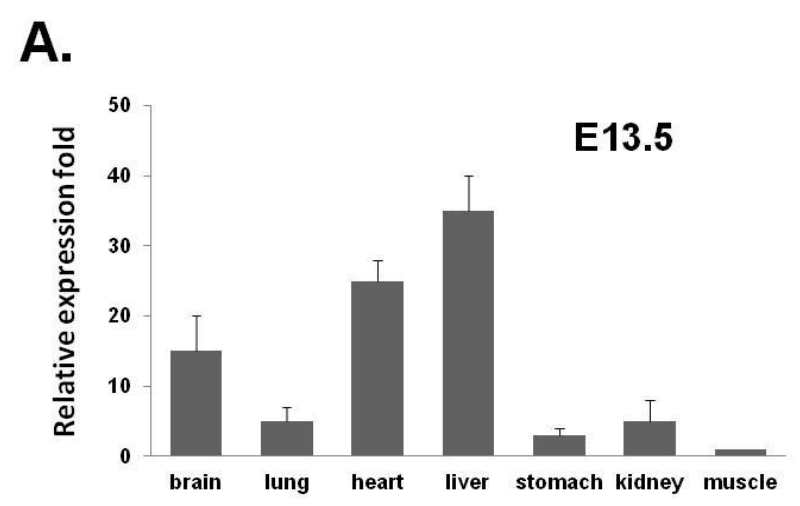

B.

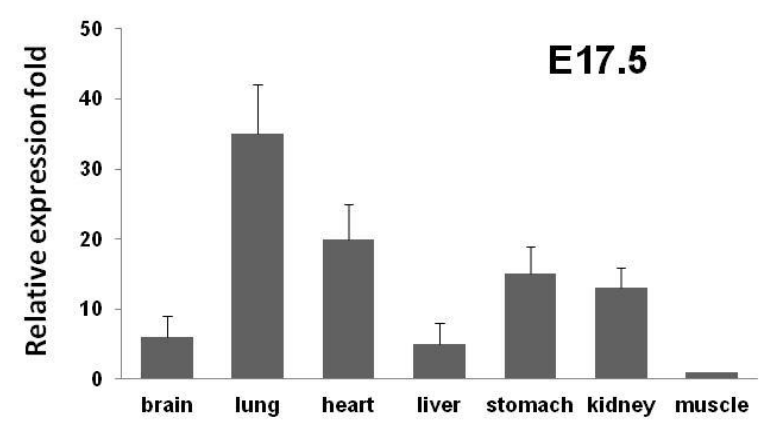

Fig. 4. NUCB2 mRNA expression in various organs of mouse fetuses at E13.5 and E17.5. NUCB2 mRNA expression in the fetal organs were analyzed by qRTPCR. In the mouse fetus at E13.5, the levels of NUCB2 mRNA were relatively higher in liver and heart than in other organs, but low in lung, stomach, and kidney (A). On the other hand, in the mouse fetus at E17.5, the levels of NUCB2 mRNA were relatively higher in lung, heart, stomach, and kidney than in other organs, but low in liver (B). All data are represented as mean $\pm \operatorname{SEM}(\mathrm{n}=5)$.

of the mouse fetus at E13.5 and E17.5 were measured by qRT-PCR and compared the differences between the two fetuses. In the mouse fetus at E13.5, the levels of NUCB2 mRNA were relatively higher in liver and heart than in other organs, but low in lung, stomach, and kidney (Fig. $4 \mathrm{~A})$. On the other hand, in the mouse fetus at E17.5, the levels of NUCB2 mRNA were relatively higher in lung, heart, stomach, and kidney than in other organs, but low in liver (Fig. 4B). Interest ingly, NUCB2 mRNA expression in the liver was dramatically reduced in the fetus at
E17.5 compared to the fetus at E13.5, whereas its expression levels in lung, stomach, and kidney were increased in the fetus at E17.5 (Fig. 4).

\section{DISCUSSION}

We previously reported that NUCB2/nestatin-1 is expressed in the various organs of fetuses and neonates as well as adult mice. In adult mice, NUCB2 mRNA was mainly expressed in the pituitary and at relatively lower levels in the hypothalamus, spleen, thymus, heart, liver, and muscle (Chung et al., 2013; Kim et al., 2014). Interestingly, expression in reproductive organs such as the testis, epididymis, ovary, and uterus was significantly higher than in the hypothalamus (Chung et al., 2013; Kim et al., 2014). On the other hand, NUCB2/nesfatin-1 expressed in the fetus and neonate was relatively higher in lung, kidney, and stomach than other organs. Comparing the level of NUCB2 mRNA expression in fetuses and neonates with that in adult mice, expression level was decreased in the stomach, but increased in the kidney of adult mice. These results suggest that NUCB2/ nesfatin-1 may be involved in the development and physiological function of mouse organs (Chung et al., 2013).

In previous study, we used the fetus at embryonic day (E) 18.5 to examine the levels of NUCB2 mRNA and nesfatin1 protein expression in the organs (Chung et al., 2013). It is well known that the formation of main organs during mouse fetal development begins at E8.0 to E10.0 (Tam \& Behringer, 1997; Zorn \& Wells, 2009). Considering this fact, it is critical to examine the expression of organogenesis-related genes during this period when organ formation begins. However, the size of the fetus at about E10.0 when organ formation begins is too small to obtain organs. Thus, it is impossible to examine gene expression by qRT-PCR analysis. To overcome this obstacle, we used high-sensitive ISH technique instead of qRT-PCR. The advantage of ISH is that it can identify specific gene expression sites where it is expressed at even low levels. Moreover, it is not necessary to 
harvest fetal organs, since tissue sections are used in ISH. (Baumgart et al., 1997; Chotteau-Lelievre et al., 2006; Stylianopoulou et al., 2012). Considering these advantages of ISH, we performed ISH to examine NUCB 2 mRNA expression in the fetal organs at E10.5. As a result of ISH, NUCB2 mRNA was localized in the liver and heart of mouse fetus at E10.5, whereas no positive signals were detected in other organs. To further verify the localization of NUCB2 mRNA expression in the liver and heart, we next performed immunofluorescence staining for nesfatin-1 protein encoded in NUCB2 gene. In accordance with ISH results, nesfatin-1 protein was expressed in the fetal liver and heart. The fact that NUCB2 mRNA and nesfatin-1 protein were expressed in the same sites indicates that NUCB2 mRNA is certainly expressed in the liver and heart. Given the ISH and IHC results, NUCB2/nesfatin-1 may be involved in the development of the liver and heart at the beginning of organ formation.

Similar to our study, gene expression of leptin known to involve in the regulation of energy balance and appetite like nesfatin-1 was localized to specific sites in the mouse fetus by ISH. High levels of gene expression of leptin were observed in the placenta, fetal cartilage, and hair follicles in the mouse fetus at E14.5, suggesting that leptin may play a role in the growth and development of the fetus (Hoggard et al., 1997; Warchol et al., 2014). Ghrelin is also a participant in regulating the complex process of energy homeostasis by showing the opposite function of nesfatin-1 to appetite. At early stages of mouse fetal development, ghrelin was expressed in the primitive epithelium of lungs, and decreased in levels of expression with gestational age. The fetal lung is one of the first to express ghrelin during development and might be considered a new source of circulating fetal ghrelin (Santos et al., 2006; Warchol et al., 2014). Taken together, these results suggest nesfatin-1 may also be involved in the growth and development of mouse fetus.

To determine the level of NUCB2 mRNA in the fetuses as early as possible to get organs at the developmental stage of the moue, we used the fetuses at E13.5. In addition, their levels of NUCB2 mRNA were compared with those of the fetuses at E17.5. In the mouse fetus at E13.5, the levels of NUCB2 mRNA were relatively higher in liver and heart than in other organs, but low in lung, stomach, and kidney similar to ISH result. On the other hand, in the mouse fetus at E17.5, the levels of NUCB2 mRNA were relatively higher in lung, heart, stomach, and kidney than in other organs, but low in liver. In our previous study using the mouse fetus at E18.5, the levels of NUCB2 mRNA and nesfatin-1 protein expressed in the organs were also relatively high in lung, heart, stomach, and kidney but low in liver, similar to those of in mouse fetus at E17.5 (Chung et al., 2013). These differences in the expression of NUCB2/nesfatin-1 between the two fetuses at the developmental stage suggest that NUCB2/ nesfatin-1 may play an important role in organogenesis during mouse fetal development.

We demonstrated here for the first time that NUCB2 mRNA was localized in the liver and heart of mouse fetus at E10.5 by ISH and nesfatin-1 protein was detected in the same organs by IHC. In addition, the levels of NUCB2 mRNA expressed in liver and heart at E13.5 were different compared to that of the mouse fetus at E17.5. These results suggest that NUCB2/nesfatin-1 may play an important role in the development and physiological function of liver and heart during organogenesis in the mouse fetus. In the future, we need more study on the function of NUCB2/nesfatin-1, which is highly expressed in the liver and heart at the beginning of organogenesis during mouse fetal development.

\section{ACKNOWLEDGEMENTS}

This work was supported by a basic research grant from Seoul Women's University (2018).

\section{REFERENCES}

Barnikol-Watanabe S, Gross NA, Gotz H, Henkel T, Karabi- 
nos A, Kratzin H, Barnikol HU, Hilschmann N (1994) Human protein NEFA, a novel DNA binding/EF-hand/ leucine zipper protein. Molecular cloning and sequence analysis of the cDNA, isolation and characterization of the protein. Biol Chem Hoppe Seyler 375:497-512.

Baskin LS, Hayward SW, Sutherland RA, DiSandro MJ, Thomson AA, Goodman J, Cunha GR (1996) Mesenchymal-epithelial interactions in the bladder. World $\mathrm{J}$ Urol 14:301-309.

Baumgart E, Schad A, Völkl A, Fahimi HD (1997) Detection of mRNAs encoding peroxisomal proteins by nonradioactive in situ hybridization with digoxigenin-labelled cRNAs. Histochem Cell Biol 108:371-379.

Brailoiu GC, Dun SL, Brailoiu E, Inan S, Yang J, Chang JK, Dun NJ (2007) Nesfatin-1: Distribution and interaction with a $\mathrm{G}$ protein-coupled receptor in the rat brain. Endocrinology 148:5088-5094.

Chotteau-Lelievre A, Dolle P, Gofflot F (2006) Expression analysis of murine genes using in situ hybridization with radioactive and nonradioactively labeled RNA probes. Methods Mol Biol 326:61-87.

Chung Y, Jung E, Kim H, Kim J, Yang H (2013) Expression of nesfatin-1/NUCB2 in fetal, neonatal and adult mice. Dev Reprod 17:461-467.

Chung Y, Kim J, Im E, Kim H, Yang H (2015) Progesterone and 17ß-estradiol regulate expression of nesfatin-1/ NUBC2 in mouse pituitary gland. Peptides 63:4-9.

Chung Y, Kim H, Seon S, Yang H (2017) Serum cytokine levels are related to nesfatin-1/NUCB2 expression in the implantation sites of spontaneous abortion model of $\mathrm{CBA} / \mathrm{j} \times \mathrm{DBA} / 2$ mice. Dev Reprod 21:35-46.

Cunha GR, Baskin L (2016) Mesenchymal-epithelial interaction techniques. Differentiation 91:20-27.

Foo KS, Brismar H, Broberger C (2008) Distribution and neuropeptide coexistence of nucleobindin-2 mRNA/ nesfatin like immunoreactivityin the rat CNS. Neuroscience 156:563-579.

Garcia-Galiano D, Navarro VM, Gaytan F, Tena-Sempere
M (2010) Expanding roles of NUCB2/nesfatin-1 in neuroendocrine regulation. J Mol Endocrinol 45:281-290.

Garcia-Galiano D, Pineda R, Ilhan T, Castellano JM, RuizPino F, Sanchez-Garrido MA, Vazquez MJ, Sangiao-Alvarellos S, Romero-Ruiz A, Pinilla L, Dieguez C, Gaytan F, Tena-Sempere M (2012) Cellular distribution, regulated expression, and functional role of the anorexigenic peptide, NUCB2/ nesfatin-1, in the testis. Endocrinology 153:1959-1971.

Goebel M, Stengel A, Wang L, Tache Y (2009) Restraint stress activates nesfatin-1-immunoreactive brain nuclei in rats. Brain Res 1300:114-124.

Goebel-Stengel M, Wang L, Stengel A, Tache Y (2011) Localization of nesfatin-1 neurons in the mouse brain and functional implication. Brain Res 1396:20-34.

Gonzalez R, Tiwari A, Unniappan S (2009) Pancreatic beta cells colocalize insulin and pronesfatin immunoreactivity in rodents. Biochem Biophys Res Commun 381:643648.

Hoggard N, Hunter L, Duncan JS, Williams LM, Trayhurn P, Mercer JG (1997) Leptin and leptin receptor mRN and protein expressio in the murine fetus and placenta. Proc Natl Acad Sci USA 94:11073-11078.

Jiang S, Zhou W, Zhang X, Wang D, Zhu H, Hong M, Gong Y, Ye J, Fang F (2016) Developmental expression and distribution of nesfatin-1/NUCB2 in the canine digestive system. Acta Histochem 118:90-96.

Kim J, Chung Y, Kim H, Im E, Lee H, Yang H (2014) The tissue distribution of nesfatin-1/NUCB2 in mouse. Dev Reprod 18:301-309.

Miura K, Titani K, Kurosawa Y, Kanai Y (1992) Molecular cloning of nucleobindin, a novel DNA-binding protein that contains both a signal peptide and a leucine zipper structure. Biochem Biophys Res Commun 187:375-380.

Nozawa S, Kimura T, Kurishima M, Mimura K, Saeki K, Miki Y, Oda H, Mori A, Momota Y, Azakami D, Ishioka K (2016) Analyses of a satiety factor NUCB2/nesfatin1 ; gene expressions and modulation by different dietary 
components in dogs. J Vet Med Sci 78:411-417.

Oh-I S, Shimizu H, Satoh T, Okada S, Adachi S, Inoue K, Eguchi H, Yamamoto M, Imaki T, Hashimoto $\mathrm{K}$, Tsuchiya T, Monden T, Horiguchi K, Yamada M, Mori M (2006) Identification of nesfatin-1 as a satiety molecule in the hypothalamus. Nature 443:709-712.

Prinz P, Goebel-Stengel M, Teuffel P, Rose M, Klapp BF, Stengel A (2016) Peripheral and central localization of the nesfatin-1 receptor using autoradiography in rats. Biochem Biophys Res Commun 470:521-527.

Santos M, Bastos P, Gonzaga S, Roriz JM, Baptista MJ, Nogueira-Silva C, Melo-Rocha G, Henriques-Coelho T, Roncon-Albuquerque R Jr, Leite-Moreir AF, De Krijger RR, Tibboel D, Rottier R, Correia-Pinto J (2006) Ghrelin expression in human and rat fetal lungs and the effect of ghrelin administration in nitrofen-induced congenital diaphragmatic hernia. Pediatr Res 59:531-537.

Schalla MA, Stengel A (2018) Current understanding of the role of nesfatin-1. J Endocr Soc 10:1188-1206.

Seon S, Jeon D, Kim H, Chung Y, Choi N, Yang H (2017) Testosterone regulates NUCB2 mRNA expression in male mouse hypothalamus and pituitary gland. Dev Reprod 21:71-78.

Shimizu H, Tanaka M, Osaki A (2016) Transgenic mice overexpressing nesfatin/nucleobindin-2 are susceptible to high-fat diet-induced obesity. Nutr Diabetes 6:e201.

Stengel A, Goebel M, Wang L, Tache Y (2010) Abdominal surgery activates nesfatin-1 immunoreactive brain nuclei in rats. Peptides 31:263-270.

Stengel A, Goebel-Stengel M, Wang L, Kato I, Mori M, Tache Y (2012) Nesfatin-1(30-59) but not the N- and Cterminal fragments, nesfatin-1(1-29) and nesfatin-1(6082) injected intracerebroventricularly decreases dark phase food intake by increasing inter-meal intervals in mice. Peptides 35:143-148.

Stylianopoulou E, Lykidis D, Ypsilantis P, Simopoulos C, Skavdis G, Grigoriou M (2012) A rapid and highly sensitive method of non radioactive colorimetric in situ hybridization for the detection of mRNA on tissue sections. PLOS ONE 7:e33898.

Tam PP, Behringer RR (1997) Mouse gastrulation: The formation of a mammalian body plan. Mech Dev 68:3-25.

Warchol M, Krauss H, Wojciechowska M, Opala T, Pieta B, Zukiewicz-Sobczak W, Kupsz J, Grochowalska A (2014) The role of ghrelin, leptin and insulin in foetal development. Ann Agric Environ Med 21:349-352.

Xu L, Bloem B, Gaszner B, Roubos EW, Kozicz T (2009) Sex-specific effects of fasting on urocortin 1, cocaineand amphetamine-regulated transcript peptide and nesfatin-1 expression in the rat Edinger-Westphal nucleus. Neuroscience 162:1141-1149.

Zorn AM, Wells JM (2009) Vertebrate endoderm development and organ formation. Annu Rev Cell Dev Biol 25: $221-251$ 